
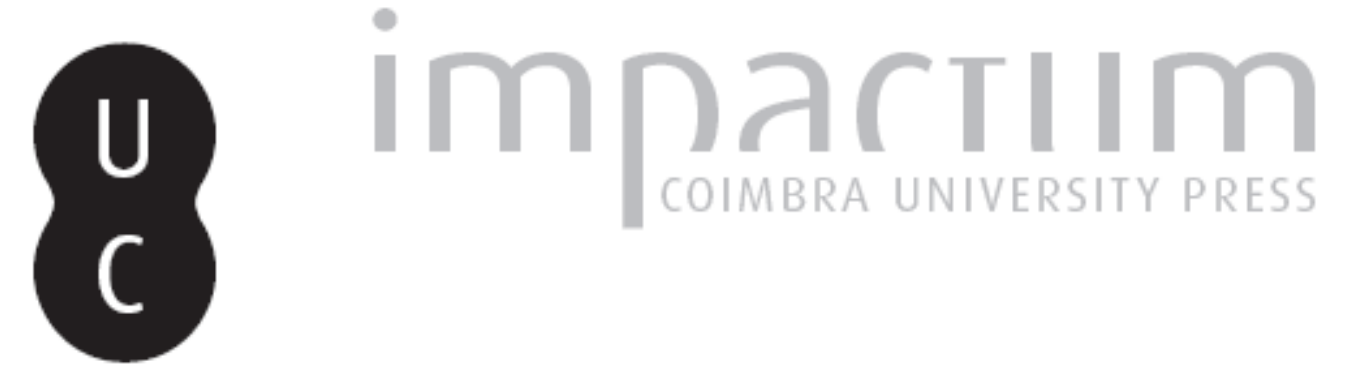

\title{
António Oliveira Marreca: um economista no parlamento
}

Autor(es): Bastien, Carlos; Campos, Cecília

Publicado por: Faculdade de Economia da Universidade de Coimbra

URL persistente:

URI:http://hdl.handle.net/10316.2/26045

DOI:

DOI:http://dx.doi.org/10.14195/2183-203X_27_1

Accessed : $\quad$ 26-Apr-2023 11:09:09

A navegação consulta e descarregamento dos títulos inseridos nas Bibliotecas Digitais UC Digitalis, UC Pombalina e UC Impactum, pressupõem a aceitação plena e sem reservas dos Termos e Condições de Uso destas Bibliotecas Digitais, disponíveis em https://digitalis.uc.pt/pt-pt/termos.

Conforme exposto nos referidos Termos e Condições de Uso, o descarregamento de títulos de acesso restrito requer uma licença válida de autorização devendo o utilizador aceder ao(s) documento(s) a partir de um endereço de IP da instituição detentora da supramencionada licença.

Ao utilizador é apenas permitido o descarregamento para uso pessoal, pelo que o emprego do(s) título(s) descarregado(s) para outro fim, designadamente comercial, carece de autorização do respetivo autor ou editor da obra.

Na medida em que todas as obras da UC Digitalis se encontram protegidas pelo Código do Direito de Autor e Direitos Conexos e demais legislação aplicável, toda a cópia, parcial ou total, deste documento, nos casos em que é legalmente admitida, deverá conter ou fazer-se acompanhar por este aviso.

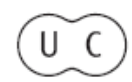




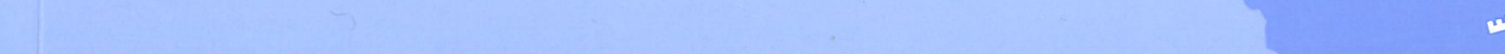

\section{N $\odot$ I $A$ S G O N}

\section{CARLOS BASTIEN/ ANTÓNIO OLIVEIRA MARRECA: UM ECONOMISTA NO PARLAMENTO CECILIA CAMPOS}

\section{DAN LI/}

MANUEL PORTUGAL FERREIRA

INTERNAL AND EXTERNAL FACTORS ON FIRM'S TRANSFER PRICING DECISIONS: INSIGHTS FROM ORGANIZATION STUDIES

CARLOS F. ALVES

O EFEITO DA FAMILIA JURIIDICA NA TRANSPOSIÇÃO DA DIRECTIVA DAS OFERTAS PÚBLICAS DE AQUISIÇÃO

PATRICIA MOURA E SÁ/ OLIVIA FERNANDES SINTRA
MODERNIZAÇÃO ADMINISTRATIVA E GESTÃO DA QUALIDADE: UM ESTUDO EMPÍRICO NOS MUNICÍPIOS PORTUGUESES

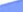
$-$ 4

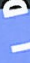




\section{António Oliveira Marreca: um economista no parlamento}

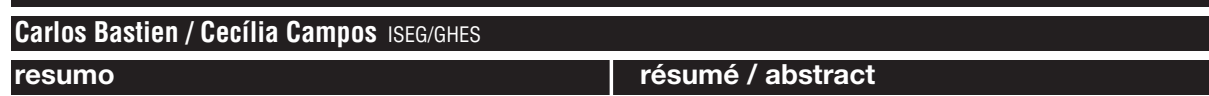

António Oliveira Marreca foi um economista português (e por um breve período também professor de economia política) de meados do século XIX que, a partir de uma certa fase, se revelou desalinhado do cânone liberal dominante e se aproximou das perspectivas do "sistema nacional de economia política". A sua acção enquanto economista teórico e enquanto doutrinador do nacionalismo desenvolvimentista foi já estudada. A sua intervenção no campo da política económica e financeira permanece mais obscura. Caracterizar as posições que Oliveira Marreca assumiu neste último plano - em especial no âmbito da sua actividade parlamentar -, avaliar o respectivo impacto e esclarecer a forma como tais posições se articularam com as concepções económicas mais gerais deste autor e da sua época são os objectivos deste paper.
António Oliveira Marreca est un économiste portugais (et, pendant une courte période, professeur d'économie polítique également) du milieu du XIXème siècle qui, à partir d'une certaine étape, s'est libéré du dogme libéral dominant pour se rapprocher des perspectives du "système national d'économie politique". Son action en tant qu' économiste théorique et doctrinaire du nationalisme développementiste a déjà été étudiée. Son intervention dans le domaine de la politique économique et financière reste plus obscure. Caractériser les positions qu'a assumées Oliveira Marreca dans ce dernier domaine - notamment dans le cadre de son action parlementaire -, évaluer leur impact et éclaircir la manière par laquelle de telles positions se sont articulées avec ses propres conceptions économiques et celles de son époque, tels sont les objectifs de cet article.

António Oliveira Marreca was a Portuguese economist from the mid $19^{\text {th }}$ century as well as a professor of political economy for a brief period. At a certain stage, his deviation from the prevailing liberal canon became apparent as he moved closer to the perspectives of a "national system of political economy". His action as a theoretical economist and as a doctrinaire of nationalist developmentalism has already been studied. Nevertheless, his intervention in the field of economic and financial policy remains somewhat obscure. This paper aims to characterize Oliveira Marreca's ideas regarding these topics, in particular those revealed during his parliamentary activity. It will assess their impact and iluminate the way his positions fitted within his broader economic ideas as well as within the prevailing economic thought of his period. 
"O sr. Marreca considerou a questão da protecção e da liberdade de comércio em todos os seus variados aspectos e as considerações que fez no Relatório da Exposição da Indústria em 1849, é o que temos de certo de mais completo e sistemático em tão importante problema económico."

A. P. Lopes de Mendonça (1855)

\section{Introdução}

António Oliveira Marreca, nascido em Santarém em 1805 e falecido em Lisboa em 1889, foi um personagem multifacetado da vida pública portuguesa de meados do século XIX designadamente enquanto autor de romances históricos, publicista, animador de clubes de intelectuais, professor, administrador de serviços públicos, dirigente político e economista.

De entre essas múltiplas facetas interessa por ora destacar a de economista, a qual foi pontualmente estudada ainda no decurso do século XIX (Freitas, 1889) bem como em diversos trabalhos produzidos nos últimos vinte e cinco anos. Neles foi sucessivamente considerada a posição de Oliveira Marreca no terreno da teoria económica (Castro 1980; Almodovar 1995; Bastien, 2002), a sua acção de doutrinação em prol da industrialização do país (Serra, 1980; Barreira, 1983), a sua intervenção no lançamento do sistema estatístico nacional (Serrão, 1978), e foi até publicada uma compilação, lamentavelmente incompleta, dos seus textos económicos (Marreca, 1983).

\section{É objectivo do presente paper retomar o discurso económico de Oliveira Marreca numa} perspectiva não considerada nem nos estudos nem na compilação supra citados; isto é, analisar o discurso político-económico deste economista em sede parlamentar e, na medida do possível, avaliar o impacto desse mesmo discurso na vida social e em particular no sistema político. Atenda-se no entanto a que na época em que Marreca assumiu a condição de deputado os economistas eram actores políticos secundários, designadamente porque eram em pequeno número, porque não se afirmavam colectivamente como grupo profissional especializado e também porque, em parte em consequência destas duas circunstâncias, a defesa dos diversos interesses presentes no confronto parlamentar privilegiava o recurso a uma retórica económica legitimante e superficial em prejuízo de eventuais reflexões apoiadas em argumentos elaborados visando racionalizar e ordenar a política económica.

Em qualquer caso, pretende-se por ora, mediante consideração de um caso concreto, contribuir para uma história analítica do processo de formulação das políticas económicas e em particular para o esclarecimento do papel dos economistas nesse processo num contexto parlamentar e liberal. Está aqui em causa um programa de investigação informal em história das ideias económicas que não se esgota no recenseamento mais ou menos crítico dos livros, artigos, panfletos,... publicados pelos diversos economistas, mas antes um programa que procura atender também ao significado social dessas ideias e às múltiplas formas da intervenção pública - na circunstância a parlamentar - em que elas se expressam.

Perspectivas semelhantes, ao menos no sentido em que analisam a acção dos economistas e as ideias económicas num mesmo contexto institucional e social, presidiram a estudos recentes sobre o caso italiano (Augello e Guidi, 2002), sobre o caso espanhol (Martorell Linares, 2000), menos recente mas ainda plenamente actualizado, sobre o caso inglês (Fetter, 1980) e ainda a um estudo de natureza comparativa contemplando vários países europeus, o Japão e os Estados Unidos da América (Augello e Guidi, 2005).

Contribuir a prazo para a determinação da medida em que a acção parlamentar dos economistas portugueses obedece a um padrão geral ou antes evidencia singularidades é outro objectivo deste paper. 
Marreca teve uma acção política continuada ao longo da vida. Ainda estudante aderiu à causa liberal, o que Ihe valeu a prisão logo em 1828 e o exílio em Londres no ano seguinte. Em 1834, com o termo da guerra civil, regressou a Portugal para, após uma participação ambígua no período da Revolução Setembrista, radicalizar as suas posições e se aproximar do que sobrava do setembrismo radical num combate porfiado aos governos de Costa Cabral, nomeadamente ao integrar a junta revolucionária de Lisboa em 1846.

Em 1848, não obstante ter antes considerado que "as revoluções são perigosas porque comprometem o sossego, a fortuna e a existência dos povos" (Marreca, 1838: 154), integrou a direcção da primeira revolta republicana que ocorreu em Portugal, revelando-se daí em diante uma figura de referência do republicanismo português. Mais tarde, a partir do início dos anos 70 , reforçou essa imagem quando participou nas já então mais organizadas forças republicanas, nomeadamente ao presidir ao primeiro grande comício que estas realizaram, ao integrar a primeira equipa dirigente do Partido Republicano e ao participar na redacção do respectivo programa.

A sua intervenção política, que passou ainda pela participação no Clube dos Lunáticos, pela direcção do Partido Histórico Progressista e pela revolta da Janeirinha, em 1868, surgia assim associada a um liberalismo crítico da monarquia constitucional em geral e do projecto regenerador em particular, que Marreca considerava incapaz de produzir soluções para os grandes problemas da sociedade portuguesa, sobretudo para o atraso económico. A progressiva descrença nas instituições monárquicas foi porventura a razão que o levou a recusar o lugar de Ministro da Fazenda, que lhe foi proposto na sequência da revolta da Janeirinha, bem como a recusar integrar a Câmara dos Pares ou a candidatar-se em 1871 à Câmara Municipal de Lisboa pela lista republicana.

Nacionalista convicto, Marreca recusou os pontos de vista iberistas ao mesmo tempo que reprovava as várias versões de socialismo que iam conquistando parte da intelectualidade do seu tempo. A sua filosofia política liberal apenas veio a contemporizar com uma muito limitada estatização da economia e com um pouco definido associacionismo.

Entretanto, Oliveira Marreca exerceu mandato de deputado em quatro legislaturas, entre $1838 \mathrm{e}$ 1842 (duas legislaturas) e, mais tarde, em 1851-1852 e em 1858-1859, revelando também aí uma postura que definiu inicialmente como representando "o verdadeiro centro moral e constitucional [...], um elemento médio, um poder moderador das tendências extra-constitucionais de uns para o absolutismo, de outros para a democracia" (DCD, Sessão de 21.2.1839: 351) mas que rapidamente se aproximou da extrema-esquerda liberal.

Democratização das instituições políticas, nacionalismo, intervencionismo económico moderado, valorização do papel da pequena burguesia agrária e promoção dos interesses industriais revelaram-se então as linhas orientadoras da intervenção cívica e política de Oliveira Marreca, desenvolvida tanto no âmbito parlamentar estrito como no da imprensa periódica ou até de relatórios oficiais. Não obstante, a sua acção parlamentar, para mais prosseguida numa época em que os partidos se encontravam ainda pouco institucionalizados e em que os interesses a que procurou dar voz eram igualmente pouco institucionalizados e fracos ${ }^{1}$, não revelou capacidade de mobilizar recursos políticos importantes nem de promover compromissos e alianças políticas e sociais para suporte desse seu projecto.

Em qualquer caso, aplica-se-lhe a observação genérica de um historiador da profissão economista segundo a qual "muitos dos que decidem ser economistas fazem-no porque têm um profundo interesse na política e na política económica. [...] Pode-se esperar ser útil à sociedade e, ao mesmo tempo, prosseguir objectivos científicos. [...] É por isso normal que muitos 
economistas procurem tornar-se conselheiros económicos, quando não se tornam políticos" (Wyplosz, 1999: 47).

Enquanto economista teórico, Marreca foi um autodidacta formado nos cânones da economia clássica. Construiu a sua visão da problemática económica a partir do contacto com aquele paradigma teórico e em particular com o Cathecisme e com o Cours de Jean-Baptiste Say (1815 e 1832), textos que serviram de referência básica na organização das suas lições de economia. Ao menos das que proferiu no âmbito da Associação Mercantil de Lisboa em 1837 já que das que proferiu no Instituto Industrial e Comercial de Lisboa entre 1853 e 1858 nada se sabe ${ }^{2}$.

Em Say recolheu uma abordagem da problemática económica assente num individualismo mitigado e na figura do empresário - "o que aplica os trabalhos e experiências do sábio ao ramo da sua indústria" (Marreca, 1838: 92) - enquanto elemento central do processo produtivo.

Foi ainda sob a influência deste economista francês que dissertou sobre os mercados, notando que os produtos se trocam sempre por produtos e recusando a ideia de crises de sobreprodução. Nessa linha tomou o processo de desenvolvimento como consequência da divisão do trabalho, do aumento das trocas entre os vários sectores da economia e do correlativo alargamento dos mercados. Em matéria de teoria das relações internacionais, o professor do curso de economia política da Associação Mercantil de Lisboa revelava ainda nos anos 30 aceitar a teoria clássica do comércio internacional, nela fundando uma atitude favorável ao livre câmbio.

No decorrer da década seguinte este economista escalabitano adquiriu uma clara percepção dos limites analíticos da economia clássica e aproximou-se das concepções da chamada escola nacional de economia política de Friedrich List $(1841 / 1991)^{3}$, numa viragem que apesar de tudo parece ter decorrido mais da sua reflexão sobre o concreto português que de eventuais ecos dos "debates criativos por que passou a economia clássica" na década de 1830 (Blaug, 1958: 150).

Não obstante a inexistência nesta segunda fase de uma exposição teórica clara equivalente à plasmada nas Noções (Marreca, 1838: 67-197), a visão de Marreca assentou então numa nova metodologia e privilegiou três tópicos: a crítica da economia cosmopolita, a teoria do valor e das forças produtivas e a caracterização das diversas fases do processo de desenvolvimento económico.

Em matéria de metodologia passou a privilegiar a abordagem indutiva e a minimizar o valor do saber puramente abstracto, notando mesmo que: "o ramo das ciências sociais que compreende a economia nacional conta muito poucos princípios absolutos" (Marreca, 1848: 41).

O seu afastamento da economia cosmopolita envolveu também a recusa da categoria de indivíduo movido pelo interesse próprio enquanto categoria analítica basilar para a substituir pela de nação, que tomava como a realidade relevante na definição do comportamento individual e consequentemente a categoria fundamental da análise económica.

Relativamente à teoria do valor, Marreca, sem aprofundar a crítica da teoria subjectiva do valor, evoluiu para uma visão dinâmica de riqueza: esta deixava de se confundir com um stock de valores existentes num determinado momento para passar a ser identificada com o potencial produtivo da nação.

Finalmente, adoptou, designadamente no Relatório do Jurado (Marreca, 1850) - o seu texto mais significativo desta segunda fase -, uma representação histórica simplificada da economia e

2 As lições de 1837 estão reunidas nas Noções Elementares de Economia Política, publicadas em 1838. É improvável que as lições dos anos 50 se situassem numa linha de continuidade teórica com as de 1838 considerando que Marreca rompera entretanto com o paradigma clássico.

3 A citação de alguns textos é acompanhada por duas datas. A primeira refere-se ao ano em que o texto nomeado foi editado; a segunda refere-se à edição por nós utilizada. 
uma tipologia dos respectivos estádios evolutivos na qual ecoavam de forma simplificada as ideias do seu referente List (vd. (Marreca, 1850: 195). Esta visão histórica era, aliás, inteiramente concordante com o romantismo, o movimento cultural que colocou "o historicismo no centro da análise" (Krabbe, 1996: 6), e que guiou a obra literária de Oliveira Marreca ${ }^{4}$.

No plano doutrinário, as ideias económicas de Oliveira Marreca conheceram uma evolução paralela. Se nos anos 30 ele se revelava um adepto do capitalismo liberal, um adepto do laissez faire laissez passer preocupado essencialmente com o papel do empresário e com o funcionamento dos mercados, a partir dos primeiros anos da década de 40 não mais aceitou a ideia que a "mão invisível" deva ser o (quase) único mecanismo regulador da actividade económica. Ao contrário, Marreca acentuou crescentemente o papel do Estado enquanto agente activo na promoção do desenvolvimento económico, designadamente na transição de uma nação no estado agrícola para o estado agrícola e industrial.

A seu ver, competia ao Estado, entre outras funções, promover uma reforma agrária parcial, dividindo e distribuindo a título gratuito propriedades fundiárias públicas por trabalhadores rurais de forma a aumentar o número de agricultores proprietários e de explorações agrícolas familiares.

Com essa medida Marreca visava impedir a expulsão dos campos de parte da população agrícola, criar um sector primário mais produtivo e próspero e alargar o mercado interno para os outros sectores da economia, sobretudo para o industrial, na lógica de um crescimento balanceado. O seu respeito pelo direito de propriedade impedia-o de propor a divisão da grande propriedade e da grande exploração agrícola não pertencentes ao Estado embora as considerasse socialmente indesejáveis.

A sua construção doutrinária tinha no entanto o seu ponto nodal na questão industrial. A partir do início dos anos 40 Marreca passou a recusar claramente a ideia de divisão internacional do trabalho tal qual era concebida pelos economistas clássicos na medida em que, em sua opinião, tal divisão condenava Portugal a permanecer como país agrícola, pobre e muito vulnerável às crises. Em contrapartida, passou a afirmar repetidamente a ideia que a criação de fábricas e 0 desenvolvimento do sector industrial era absolutamente indispensável e urgente. A seu ver, a instalação de novas indústrias dependia da iniciativa dos empresários locais apoiados pela acção do Estado através da difusão da educação técnica e sobretudo através da adopção de uma política aduaneira protectora do sector. Complementarmente, denunciou a "insistência do estrangeiro para negociar connosco tratados" (Marreca 1850: 194), em particular o tratado de comércio com a Inglaterra assinado em 1842 pelo governo de Costa Cabral, o qual estabelecendo a mais completa liberdade de comércio e navegação, agravou significativamente o défice comercial português ${ }^{5}$. Porventura tendo em mente alguns casos já em curso, admitiu ainda que o impulso industrializante pudesse ser marginalmente potenciado pelo investimento estrangeiro.

Outro tópico importante na construção doutrinária de Oliveira Marreca era o dos transportes. Sem ser muito específico sobre a configuração da rede a criar ou a desenvolver, tinha claro que o drástico aperfeiçoamento dos transportes internos era crucial para a integração definitiva do espaço económico nacional, para que os diversos sectores da economia portuguesa pudessem explorar as suas complementaridades e dar corpo a um sistema económico que desejava "misto", ou seja, "ao mesmo tempo agrícola, fabril e comercial" (Marreca 1843: 263), equilibrado e centrado no mercado interno.

4 Marreca foi autor de alguns romances históricos concebidos de acordo com o cânone do movimento romântico, entre os quais Conde de Castella, Maria Amaral e Manuel de Sousa Sepulveda (vd. Chaves 1980: 37-38).

5 "A abertura da economia portuguesa e as tendências livre-cambistas defendidas pelo governo cartista e enquadradas no tratado comercial de 1842 tiveram consequências imediatas: não só o défice comercial subiu em flecha como o transporte das mercadorias exportadas e importadas ficou ainda mais controlado por estrangeiros." (Sideri, 1978: 218). 
Em matéria de relações económicas externas a doutrina de Marreca era, na sua fase madura, avessa ao livre cambismo, contrária à ideia do zollverein ibérico defendido por alguns intelectuais da sua geração, desvalorizadora de uma ligação forte com a Europa e adepta de uma relação privilegiada com as colónias, não obstante nos anos 30 ter sugerido ser tal ligação um fardo financeiro indesejável.

A doutrina desenvolvimentista de Marreca integrava também algumas indicações a respeito da moeda, do crédito e das finanças públicas.

Relativamente à moeda, considerou que a protecção externa teria o efeito benéfico de evitar a sangria da circulação metálica, opôs-se à ideia de circulação puramente convencional (ao papel moeda) e preconizou a criação de uma "moeda papel" garantida por reservas metálicas a emitir pelos "estabelecimentos de crédito" (Marreca, 1843: 244). Sustentou adicionalmente a necessidade de manter baixa a taxa de juro, contando para isso com o aumento da oferta de capitais proporcionada pelo progresso do sistema bancário e advogou mesmo o "empréstimo gratuito de capitais do Estado a empresários activos e probos” (Marreca, 1848: 44).

À semelhança de List, Marreca considerava que o sistema de crédito era uma das importantes criações da administração moderna, já que permitia superar a usura e viabilizar o progresso das actividades agrícolas e industriais. Em consequência, propôs a criação de novos bancos a somar aos dois existentes no país em meados do século XIX - sugerindo pontualmente que por razões de credibilidade esses novos bancos poderiam ser públicos e recomendou a disseminação de agências bancárias e de caixas económicas pelas diversas regiões do país.

Nos escritos da primeira fase, Marreca expressou posições clássicas a respeito das finanças públicas em geral, nomeadamente ao sublinhar a necessidade de a actividade financeira do Estado se manter num nível baixo e em equilíbrio orçamental. À semelhança de Say, considerou que "o tributo pesa sobre as rendas e algumas vezes também sobre os capitais dos cidadãos; e como tal o melhor é o mais pequeno, e depois do mais pequeno o mais igual" (Marreca, 1848: 183). Contudo, na sua fase madura, ainda que sem discutir as implicações de eventual desequilíbrio orçamental e sem ser inteiramente claro relativamente aos efeitos da dívida pública, reclamou a baixa de alguns impostos que incidiam sobre os produtos industriais e sobre o consumo (sugerindo que a perda de receita daí decorrente poderia ser parcialmente compensada pela das tarifas externas) ao mesmo tempo que sustentava que "ao Estado pertenceriam os trabalhos mais dispendiosos de irrigação, esgotamento, canalização, e estradas" (Marreca, 1850: 184).

\section{O parlamentar}

A acção de Oliveira Marreca na Câmara dos Deputados teve por objecto privilegiado, mas não exclusivo, matérias de natureza económica e financeira - era esse o terreno em que se julgava particularmente qualificado para avaliar a situação do país, para enunciar objectivos para a acção e para esclarecer os meios necessários ao alcançar desses objectivos - e repartiu-se por algumas comissões e pela presença activa nas sessões parlamentares plenárias.

Uma parte da sua intervenção política realizou-se assim no âmbito de algumas comissões ad hoc ou de funcionamento menos regular, como foi o caso da Comissão de Infracções, em 1840, da Comissão encarregada de dar parecer sobre a nomeação de uma comissão de inquérito à extinção da roda do sal de Setúbal ${ }^{6}$, da qual foi relator em 1852, e da Comissão de Comércio e Artes, em que participou em 1858. Integrou ainda a mais importante das comissões, a da Fazenda, em 1852. 
No âmbito do plenário da Câmara dos Deputados, onde participou nos mais importantes debates do seu tempo, confrontou frequentemente, e por vezes longamente, opiniões com vários dos seus colegas economistas ${ }^{7}$. Através de múltiplas intervenções, da subscrição e apresentação de propostas e do voto definiu as suas posições em matéria de política económica e financeira, procurou influenciar a agenda pública e pressionar mudanças na orientação governamental.

A sua primeira intervenção parlamentar ocorreu em 10 de Dezembro de 1838 num debate relativo a uma petição sobre as eleições no Porto, mas só em finais de Maio do ano seguinte é que usou da palavra para se referir a temas económicos e financeiros. Aliás, dadas as continuadas dificuldades sentidas pela administração nesta última matéria, parte significativa das suas intervenções, como da generalidade dos demais economistas deputados, reportou-se justamente à situação das finanças públicas e em particular ao recorrente tema do défice orçamental.

\subsection{A questão orçamental}

Em todas as intervenções em que Oliveira Marreca se referiu ao orçamento era clara a aceitação, ainda que temperada por uma discreta flexibilidade, da ideia clássica já expressa nas suas Noções (e então aceite pela generalidade dos membros do parlamento) que o orçamento deveria ser tão reduzido quanto possível e equilibrado.

Confrontado com a necessidade de promover esse equilíbrio, começou logo num dos seus primeiros discursos por notar a necessidade de o Estado reduzir despesas, observando embora que essa redução deveria ter em conta que "as economias ainda que sejam reconhecidamente indispensáveis, e salutares, hostilizam sempre interesses estabelecidos, posto que frequentemente ataquem abusos e malversações; e por outro lado, quando são demasiadas, longe de alimentarem, extenuam o corpo social, e longe de fazer bem, redundam em detrimento do serviço público" (DCD, Sessão de 23.5.1839: 639).

De igual forma aceitou um aumento da receita mediante aumento de impostos, notando contudo que "todos sabem que eles [os impostos] só podem ser tirados dos três fundos produtivos industrial, territorial e capital - que se o imposto ou tributo absorve somente uma porção da renda que estes fundos prestam, a produção e a riqueza nacional podem continuar em progresso, que se ele absorve a totalidade da renda, a Nação fica estacionária na sua condição económica, e em fim que se o imposto chega a encetar os capitais pode paralisar-se a acção da indústria, arruinar-se e empobrecer-se o País" (idem: 640).

As limitações apontadas à superação do défice público pelas duas vias indicadas levaram Marreca a propor, sem grande êxito, uma forma insólita de "aumentar a receita pública e a renda nacional" sem necessidade de alterar sistema e taxas de impostos em vigor. Consistia essa forma em diminuir o "grande número de dias santos" que [...] roubam braços úteis à agricultura e à indústria" (idem: 641) e assim aumentar a produção e a receita fiscal.

Em qualquer caso, a grande preocupação revelada pelos economistas parlamentares incidiu por regra mais em eventuais cortes nas despesas públicas, frequentemente nas despesas com a

7 Esta figura de economista deputado incluía fundamentalmente três realidades não inteiramente assimiláveis, a saber: os economistas com formação académica ou autodidáctica equivalente; os banqueiros, empresários e gestores da administração pública ou privada que por essa circunstância pessoal ou profissional adquiriram familiaridade com as matérias económicas; os políticos profissionais a quem as vicissitudes da carreira determinaram uma atenção particular aos temas económicos. Oliveira Marreca, não obstante a sua acção enquanto administrador e a sua longa carreira política, foi essencialmente um economista deputado do primeiro tipo indicado. A sua autoridade no debate parlamentar decorreu justamente do prestígio que a sua reflexão económica realizada e publicada à margem da intervenção parlamentar obteve entre os seus pares economistas e na opinião pública ilustrada em geral. 
força armada, que no aumento das receitas. O próprio Marreca fez eco dessa ideia, ainda que sublinhando a inconveniências de cortes realizados em obediência a critérios estritamente financeiros, ao notar que "é necessário quando se trata desta matéria [a força armada] usar de muita prudência, e ainda que se não deva subordinar inteiramente a questão que nos ocupa à das despesas públicas [...]" (DCD, Sessão de 4.9.1840: 47).

Apesar destas tomadas de posição, grande parte das preocupações reveladas por este deputado aquando dos debates orçamentais respeitavam à falta de rigor e irregularidade de algumas práticas governamentais - sobretudo a não aprovação do orçamento em tempo útil, o incumprimento de limites de despesa nele fixados e a não apresentação das contas públicas práticas que, no seu entender, impediam a "boa fiscalização" (DCD, Sessão de 22.6.1840: 288) parlamentar das finanças públicas e ameaçavam as bases do constitucionalismo liberal.

\subsection{O sistema de impostos e a dívida pública}

Diversas intervenções de Oliveira Marreca na Câmara dos Deputados versaram os impostos, mas em nenhuma delas exigiu uma revisão, ou apresentou proposta de reformulação significativa, do sistema fiscal vigente.

As suas observações sobre a política fiscal reportaram-se frequentemente a questões de relevância limitada como a definição das condições em que as Câmaras Municipais poderiam lançar contribuições. A este propósito, Marreca defendeu a possibilidade de as mesmas poderem ser pagas em trabalho, em alternativa ao pagamento em dinheiro - no que se revelava pontualmente contrário ao consenso dos economistas clássicos -, e sustentou ainda que os rendimentos da pesca ficassem isentos de tais contribuições (vd. DCD, Sessão de 5.9.1840: 72).

Mais importante foi a sua aberta oposição aos expedientes financeiros a que os governos da época recorriam com alguma frequência em ordem a superar situações orçamentais menos regulares. Uma dessas situações surgiu quando o Ministro da Fazenda, António José d'Ávila, apresentou uma proposta que, violando o princípio da anuidade dos impostos, previa a continuação por alguns meses da respectiva cobrança e previa ainda a antecipação da receita que deles deveria resultar através de contratação de um empréstimo. Oliveira Marreca manifestou-se então condescendente com o prolongamento do prazo da cobrança mas absolutamente contrário à antecipação daquela receita por considerar que tal medida "torna necessárias outras autorizações desta ordem" e "usurpa todas as atribuições do poder legislativo" (DCD, Sessão de 22.6.1840: 304).

Em outros momentos, nomeadamente na sessão parlamentar de 19 de Julho de 1858, tomou a iniciativa de propor um novo imposto, um adicional aos direitos de exportação nas alfândegas de Lisboa e do Porto em substituição de adicionais a diversos impostos directos que constavam de uma proposta do governo. A justificação que apresentou para aquele novo imposto revelava uma visão aparentemente fiscalista (nessa perspectiva não divergente da que informava as medidas que se propunha substituir), já que afirmava pretender dotar o governo com os meios financeiros para pagar juros de um empréstimo sem atender aos eventuais efeitos económicos dos impostos em debate. A sua divergência com a proposta governamental revelava-se antes na preferência, que compartilhava com Say, pelos impostos indirectos relativamente aos directos, numa atitude que de alguma forma contrariava a teoria que discretamente afirmara nas suas Noções (vd. Marreca 1838: 183), mas que era compreensível à luz da ambiguidade do pensamento financeiro clássico a este respeito ${ }^{8,9}$. Em qualquer caso, a maioria parlamentar

8 As tomadas de posição dos economistas participantes dos debates fiscais no próprio parlamento inglês nesta época não revelavam uma orientação clara nesta matéria. (vd. Fetter 1980: 122 e ss).

9 Neste período, especificamente no ano económico 1857-1858, a receita originada pelos impostos indirectos era cerca do dobro da receita originada pelos directos. Nos anos seguintes, o peso da fiscalidade indirecta iria aumentar de forma significativa (vd. Mata 2001: 701). 
acabou por aceitar a sua proposta, sendo esta a única vez que tal aconteceu relativamente a matérias relevantes.

Tal como em Say, a dívida pública começou por ser vista por Marreca no plano teórico como aceitável em situações em que estivesse em causa suportar "as despesas extraordinárias de uma guerra" ou quando se tratasse de financiar "os melhoramentos internos indispensáveis que, ou não são exequíveis pelas só rendas do tributo ou não o podem ser sem aumento deste e grande vexação dos contribuintes" (idem: 185). Mais tarde, referindo-se especificamente à dívida pública interna, adoptou uma perspectiva mais genérica, mas não necessariamente diversa da anterior, ao considerar tal dívida indesejável por ser "prejudicial à indústria" (Marreca, 1850: 171), por privar esta actividade de capitais, por contribuir para o aumento da taxa de juro e por conduzir a prazo ao agravamento dos impostos.

Enquanto parlamentar Marreca não teve oportunidade de discutir aprofundadamente esta problemática. Debruçou-se algumas vezes sobre a dívida pública mas por regra em momentos em que a proximidade das datas do seu vencimento colocavam a Fazenda em situação aflitiva que chegou a descrever como de "caos e anarquia" (DCD, Sessão de 28.9.1840: 430) - e em que estavam continuamente em cogitação soluções de arriscada engenharia financeira ${ }^{10}$.

Na mais circunstanciada das suas intervenções a este respeito dirigiu-se à Câmara para, entre outras considerações, recusar a emissão de títulos do tesouro para pagamentos dos funcionários do Estado e sobretudo para chamar a atenção para os inconvenientes de uma possível suspensão dos pagamentos - considerou que tal medida resultaria na "mais danosa de todas as dívidas" (DCD, Sessão de 10.6.1839: 902) ${ }^{11}$ - e para enunciar os efeitos negativos que daí decorreriam, nomeadamente o "altear da taxa de juro" e o "minorar a criação de empresas industriais" (idem: 902). A solução que então aceitou previa o imediato equilíbrio do orçamento primário e previa a criação de um novo fundo de amortização que se encarregaria da liquidação da dívida pública. A forma de obter os recursos necessários ao funcionamento desse fundo é que diferia da prática então corrente: "Sr. Presidente, é por um modo mui simples; isto é, por meio de tributos velhos, de economias que em todo o caso se haviam de fazer, da remissão dos foros [...], da alienação dos bens nacionais já de há muito aplicados para esse fim e das dívidas activas do Tesouro já existentes!" (idem: 903). Terá sugerido esta solução sem grande convicção já que algum tempo depois se voltaria a referir à "dívida enorme, progressiva, e flanqueada por amortizações que nada amortizam" (Marreca, 1850: 172).

\subsection{O modelo desenvolvimento económico e social}

A partir dos primeiros anos da década de 40 , Marreca revelou-se fundamentalmente um precursor da economia do desenvolvimento procurando definir uma via ajustada ao caso português.

As ideias que então expressou - que, como já se referiu, revelam grande proximidade com as concepções da escola nacional de economia política - significavam um avanço relativamente ao discurso desenvolvimentista preexistente, já que iam mais longe que este na análise concreta da situação da economia portuguesa, sobretudo ao apelar ao conhecimento estatístico (vd. Marreca, 1853: 205 e ss), e ao definir uma estratégia articulada de desenvolvimento global que não desconhecia a dimensão internacional do processo de desenvolvimento.

No entanto, Marreca jamais proferiu no parlamento um discurso programático confrontando globalmente o seu projecto desenvolvimentista com o da Regeneração e jamais enunciou de

10 Entre 1852 e 1859, quando da segunda passagem de Oliveira Marreca pelo parlamento, a dívida pública correspondia a cerca de $31 \%$ do PIB (vd. Esteves 2005: 312). Para o período anterior, finais dos anos 30, não existem estimativas fiáveis.

11 Embora inserta no Diário da Câmara dos Deputados relativo à sessão de 10.6.1839, a intervenção de Marreca ocorreu no dia 6.6.1839. 
modo sistemático as medidas de política económica de longo prazo que lhe deveriam dar corpo.

Ao contrário, as suas ideias sobre política económica surgiram na Câmara dos Deputados avulsamente no âmbito de debates sectoriais, em primeiro lugar nos relativos ao sistema de transportes, ao sistema monetário e financeiro e às relações económicas externas.

\subsubsection{O sistema de transportes}

Na visão de Marreca a criação de uma rede interna de transportes tinha um papel essencial na circulação de mercadorias, na redefinição espacial das actividades industriais e, em geral, na viabilização do processo de modernização do país.

Os seus escritos posteriores a 1840 contêm múltiplas páginas com referências à urgência da construção de redes de transportes, notando mesmo que "sem melhoramento neste ramo não podemos dar um passo em nenhum outro" (Marreca, 1843: 240). No entanto, a sua intervenção parlamentar sobre este tema nem sempre se reportou às grandes questões económicas e estratégicas envolvidas.

Ausente do parlamento quando em 1850 se discutiu e aprovou a primeira lei de construção da rede de estradas, e também em 1854 quando no decurso da época fontista se debateram as grandes opções relativas à rede ferroviária, o nosso economista deputado apenas participou em debates menores, por regra centrados nos aspectos financeiros e administrativos da construção das redes de transporte e ainda assim só no decurso do seu último mandato.

Curiosamente, e sem avançar qualquer justificação para o facto, Oliveira Marreca referiu-se em diversos escritos às obras a realizar em rios e canais e à construção de estradas. Mas, ao contrário de outros economistas com concepções afins, designadamente List, nunca manifestou entusiasmo pelos transportes ferroviários, porventura porque a sua grande preocupação era a criação da infra-estrutura de sustentação do mercado interno e não tanto o reforço das ligações económicas e culturais com a Espanha e com os demais países europeus ${ }^{12}$.

Quando da apreciação de um projecto lei relativo à construção de estradas nos diferentes distritos administrativos do reino e ilhas, que votou favoravelmente, produziu um longo discurso em que referiu que "a propriedade territorial [...] tem nas estradas e vias de comunicação que se Ihe oferecem uma compensação, uma grande compensação [para um eventual aumento dos impostos]" (DCD, Sessão de 24.7.1858: 276). Defendeu então também que ante a expectativa de um mau ano agrícola se desse "maior desenvolvimento às obras públicas nos distritos onde as classes assalariadas padecessem mais por este desequilíbrio económico" (idem: 276), mas preocupou-se sobretudo em discutir os tipos e as taxas dos impostos cuja receita deveria ser afectada ao pagamento dos juros e amortizações do empréstimo a contrair para aquele efeito.

Noutro momento interveio para admoestar o governo pelo facto de este ter estabelecido em 1857 um contrato para a construção do caminho de ferro do Norte sem concurso público, ao contrário do "princípio do concurso admitido por esta câmara a respeito do caminho de ferro do sul" (DCD, Sessão de 23.2.1859: 164). Não revelou então oposição aberta à construção daquela linha mas defendeu a denúncia do respectivo contrato. Aparentemente, a sua posição não resultava de divergência com o projecto governamental, nem visava bloquear aquela construção, mas tão só impor uma reforma das práticas administrativas de modo que a realização daquele tipo de obras passasse obrigatoriamente por concursos públicos em vez das negociações directas preferidas pelo governo.

Em dois momentos a sua intervenção sobre a estratégia a seguir no sector revelou divergências importantes com as opções governamentais. Num primeiro momento ao defender a integração 
das actividades de construção e exploração da rede ferroviária no sector público - "o monopólio do Estado é muito preferível ao das companhias" (DCD, Sessão de 4.4.1859: 39) -, a seu ver uma solução vantajosa por permitir redução de custos e minimização das tarifas praticadas. Noutro momento, segundo revelação do deputado Lobo d'Ávila, ao duvidar da eficiência macroeconómica da opção governamental por "caminhos de ferro paralelos às vias de comunicação aquática" (DCD, Sessão de 22.7.1858: 242). Pensava Marreca que desse modo se minimizariam custos de construção mas pouco se acrescentaria à integração do espaço económico nacional ${ }^{13}$.

\subsubsection{As relações económicas externas}

$O$ vivo debate sobre as pautas que ocorreu em Portugal durante boa parte do século XIX não passou no essencial pelo parlamento, pelo menos nos anos em que Marreca foi deputado. Tratava-se porventura de um tema politicamente muito desgastante para os governos que se sucediam na aceitação da referência livre-cambista (ainda que nem sempre a praticassem com muito empenho) e na aceitação de uma posição de dependência relativamente aos interesses económicos e estratégicos britânicos.

Marreca, não obstante a circunstância de as suas ideias em matéria de política económica serem particularmente contraditórias com aquela visão dominante, sobretudo quando estava em causa a definição da política económica externa, nem por isso teve grandes oportunidades para as afirmar naquele forum político. Limitou-se a discordar pontualmente de propostas favoráveis ao free trade e a expender opiniões favoráveis à adopção de medidas proteccionistas.

Num debate parlamentar em que a Comissão de Comércio e Artes sugeriu a alteração da pauta proteccionista de 1837 "para o fim de alcançar nas nações estrangeiras, nos tratados que com elas houver de fazer, aquelas saudáveis vantagens que tanto são reclamadas em favor dos nossos principais produtos, e com especialidade dos nossos vinhos" (DCD, Sessão de 11.9.1839: 33) Marreca pôde apenas referir "o conflito de interesses industriais que se está debatendo fora desta Casa" (idem: 147) e manifestar discretamente a sua oposição a tal alteração.

Noutro debate sobre as relações económicas entre Portugal e Espanha, em particular no domínio do comércio de cereais, deixou clara a sua oposição, já expressa em textos doutrinários extra-parlamentares, a uma mais profunda ligação entre as economias peninsulares. Um profundo silêncio foi a sua resposta ao projecto de Zollverein ibérico sustentado pelo deputado Gomes de Castro nos seguintes termos: "é preciso [...] acabar com os portos secos; é preciso que façamos uma liga de alfândegas com a Espanha. As vantagens seriam grandes e indubitáveis. Nem poderíamos ser acusados de precipitados porque temos o exemplo desses grandes estados da Confederação Germânica que fizeram entre si a liga das alfândegas, chamada Zollverein" (DCD, Sessão de 29.7.1858: 354).

No âmbito deste mesmo debate teve oportunidade de se referir brevemente aos limites da política proteccionista, em particular do proteccionismo agrícola, ainda que o projecto em discussão se referisse a uma situação meramente temporária de escassez de cereais no país.

Alguns anos antes Marreca tinha chegado a apresentar uma proposta concreta de fixação dos direitos de importação do trigo invocando "a necessidade de proteger a nossa agricultura" (DCD, Sessão de 15.1.1841: 78). No entanto, na fase final da sua passagem pela Câmara dos

13 Os efeitos económicos decorrentes da implantação das ferrovias parecem ter sido mais importantes do que Marreca admitiu no debate parlamentar. Esses efeitos não só permitiriam superar em alguma medida a polarização da vida económica do país em Lisboa e no Porto como "o aumento da acessibilidade é inegável e, mesmo para as regiões já servidas por vias aquáticas, o aumento da rapidez e da regularidade dos transportes, libertos, por exemplo, dos problemas causados pelas cheias de Inverno e pelas secas de Verão, as vantagens não são desprezáveis." (Mata e Valério 1994: 151). 
Deputados, porventura sob a influência de List - e desconhecendo embora "o debate entre Josiah Tucker e David Hume" (Gomes 2003: 66) -, manifestou posição diversa. Abandonando então a ideia de protecção agrícola notou: "o meu programa é dar o pão barato ao consumidor. Julgo que não só o consumidor, meramente na sua qualidade de consumidor, mas que lucrará a agricultura" (DCD, Sessão de 30.7.1858: 389) ${ }^{14}$. Após uma engenhosa demonstração em que pretendia provar que trigo mais caro - dada a rigidez da procura deste bem alimentar - reduziria a procura de outros bens de origem agrícola e não só, concluía: "o pão barato é favorável aos interesses agrícolas. Se aplicarmos este princípio às fábricas, se o aplicarmos ao comércio, se o aplicarmos a todos os ramos da economia social, a cada passo acharemos provas da verdade e fecundidade dele" (idem: 390).

Tratava-se tão só de confrontar a maioria parlamentar e o governo com o tipo de proteccionismo que havia defendido em diversos textos doutrinários extra parlamentares nos quais apresentava tal política como condição de desenvolvimento sectorialmente equilibrado e garantia de independência do país.

\subsubsection{O sistema monetário e financeiro}

Foram escassas as referências deste economista deputado às questões propriamente monetárias.

Ausente do parlamento em 1854, ano em que se debateu a grande reforma monetária do período - a adesão ao padrão-ouro -, e ainda que deixando implícita a sua preferência por um sistema de base metalista, Marreca limitou-se nas suas intervenções na Câmara dos Deputados a breves considerações sobre um pedido de indemnização apresentado pelos contratadores do tabaco, os quais se diziam lesados pelo desaparecimento do papel moeda. Referiu então os efeitos da expulsão da moeda de prata pela de papel e apontou uma tendência para a desvalorização da prata após a extinção do papel moeda (vd. DCD, Sessão de 13.7.1839: 1469) em ordem a demonstrar que havia uma quebra do valor da renda paga pelos contratadores e consequentemente a inexistência de fundamento para a indemnização solicitada. Reforçou a sua opinião chamando a atenção para a volatilidade dos fenómenos monetários, do ágio em particular, sublinhando o risco inerente aos contratos a longo prazo e notando: "as flutuações que sofreu a moeda papel desde o seu estabelecimento até à sua extinção são tais que não bastaria para calculá-las antecipadamente a cabeça de Newton ou de La Place" (DCD, Sessão de 17.7.1839: 1552).

A definição de um sistema financeiro susceptível de impulsionar o processo modernizante da economia portuguesa foi um dos aspectos da doutrina deste economista que teve também tradução directa, ainda que parcial, na sua acção parlamentar, resultando fundamentalmente em duas iniciativas legislativas.

Na sequência da rejeição de um projecto de lei apresentado pela Comissão Especial de Vinhos visando a criação do Banco Agrícolo-Comercial do Douro, apresentou uma proposta, que não chegou a ser votada, de criação de dois bancos: "um banco protector da lavoura dos vinhos das províncias do Sul [sediado em Lisboa] e outro igual na cidade do Porto protector desta lavoura nas províncias do Norte" (DCD, Sessão de 12.3.1841: 151).

Atribuía-Ihes naturalmente funções típicas da actividade bancária, designadamente, "emprestar aos lavradores das respectivas províncias, sob hipoteca dos seus vinhos ou vinhas, as quantias de que carecem para o amanho e fabrico dos mesmos à razão de cinco por cento ao ano" (idem: 151). Menos típicas eram algumas actividades de apoio à exportação expressamente cometidas aos dois bancos em causa, sobretudo a obrigatoriedade de manterem depósitos de vinhos em portos da Europa e da América. 
Ainda que Marreca tenha chegado a considerar em teoria as vantagens de um sistema bancário público, este projecto deixava claro que estes bancos agrícolas seriam privados ainda que a iniciativa da sua criação fosse estatal, já que a proposta estabelecia que competia ao governo promover a subscrição do capital. Sustentando que era obrigação do Estado uma "intervenção organizadora e de protecção positiva" (Marreca 1850: 176), estabelecia um regime de isenção total de impostos, tanto sobre o capital como sobre as transacções, e a garantia aos accionistas de um juro anual de $3 \%$ acrescido da concessão de "recompensas honoríficas" a todos aqueles que detivessem um mínimo de oitenta acções.

Outra proposta relativa ao sistema financeiro, porventura influenciada pelo elemento associacionista da sua mundivisão e norteada por uma preocupação imediatamente social, visava a criação de caixas económicas, algo até então inexistente em Portugal. Marreca considerava que a principal via de solução da questão social estava na divisão da propriedade, muito embora a questão só se resolvesse definitivamente "pela tenaz agência, pela constante perseverança, pela bem regulada economia dessas infelizes classes [trabalhadoras]" (DCD, Sessão de 6.7.1839: 1370).

Numa retórica empolgada, diversa do seu estilo habitual mas porventura dominada pela intenção de seduzir aquelas classes, propunha: "o pecúlio do trabalhador, e artista, o vintém de todos os dias, os escassos cinco reis, suor do homem laborioso, roubados à intemperança ao vício da embriaguez, à cobiça do jogo, ao engodo das rifas e das lotarias, [...] essas pequenas sobras, essas previdentes acumulações, esses capitais imperceptíveis do pobre, que pela sua isolação não podiam ser metidos na circulação produtiva, vão agregados uns aos outros formar [...] uma soma considerável e frutificar no fundo das caixas económicas" (idem: 1370).

O que estava em causa era a criação de uma rede de dezassete caixas económicas, uma em cada capital de distrito. À semelhança do que previa para os bancos rurais, era também às autoridades que cometia a responsabilidade de promover a criação destas organizações e até, se necessário, de prover os seus fundos. As operações activas que Ihes destinava consistiam em empréstimos sobre penhores, empréstimos aos lavradores e ainda a aquisição de acções dos bancos e apólices da Junta do Crédito Público. Aos trabalhadores depositantes era garantido um juro anual de $5 \%$ e era também garantida preferência na admissão em empregos nas obras públicas.

A mais relevante preocupação social residia no entanto na disposição que previa a constituição de uma rede de segurança social embrionária e semi-pública, de tal modo que: "todo o indivíduo que desde a idade de 20 até 30 anos começar e continuar a depositar um tostão por semana numa caixa económica, quando chegar aos 60 anos de idade receberá, afora o juro do seu depósito, uma pensão anual e vitalícia de $24 \$ 000$ reis, paga à custa do rendimento de todas as caixas económicas." (idem: 1375).

Apesar do empenho de Marreca neste projecto, o mais que conseguiu foi que a Comissão de Administração Pública emitisse, tardiamente, um parecer favorável (vd. DCD, Sessão de 11.8.1840: 180), mas não a sua discussão em sessão plenária e menos ainda a sua aprovação ${ }^{15}$.

15 Alguns testemunhos da época sugerem uma fraca eficácia da prática parlamentar, que não só a dos deputados economistas. Um viajante prussiano descreveu tal prática nos seguintes termos: "[...] a sala das cortes afigura-se quase sempre menos como uma reunião civilizada e urbana de que como a espelunca de um clube revolucionário; não se trata aqui de frases acetinadas, nem de ostentações de cortesia. Está-se como no meio da rua; atiram-se uns aos outros, por assim dizer, com lodo e pedras da calçada; em vez de sal ático, enfeitam-se os discursos com as mais grosseiras injúrias, des gros mots... Um membro da oposição diz a um ministro da Coroa sob a tua administração é tudo concussão e simonia. O ministro levanta-se e interrompe: quando tu estiveste no gabinete, roubaste com muito maior atrevimento. Não, clama o outro, tu és o maior dos ladrões. O presidente faz em vão soar a campainha, com toda a força do seu braço; ninguém faz caso de tal, ninguém ouve o que os outros dizem; a maior parte levantam-se, agitam-se em torno dos seus lugares, e peroram simultaneamente, ao passo que as galerias, fazendo também descer à sala os ecos do seu tumulto, associam-se a esta cena de orgia." (Lichnowsky, 1845/2005: 99-100). 


\section{Conclusões}

Oliveira Marreca foi antes do mais um economista que após uma fase em que deu expressão a um pensamento clássico tomou por cânone teórico a escola nacional de economia política. No plano doutrinário evoluiu de uma posição favorável à liberalização económica interna e externa para a defesa de uma liberalização interna complementada por uma intervenção estatal protectora externa, que considerou condição sine qua non do processo de modernização da economia portuguesa.

Esta dupla rotura reflectiu-se, ainda que de uma forma pálida, na sua intervenção parlamentar. A definição da política económica é um processo complexo e conflituante no qual interagem elementos do senso comum, manifestações directas de interesses económicos, considerações de oportunidade política,... mas também concepções teóricas e doutrinárias. Não se tratando pois de uma mera tradução destas concepções, as orientações de política económica não deixam de ser por elas influenciadas, sobretudo quando quem formula tais orientações dispõe de uma competência especializada, como era o caso deste deputado. A pouca frequência dos debates sobre temas em que as diferenciações teóricas e doutrinárias eram marcantes, aliada à não preocupação dos deputados em revelar o sistema teórico que influenciava as suas posições, contribuíram certamente para a citada palidez.

Enquanto deputado, Marreca nunca teve oportunidade de expor de forma sistemática as suas concepções no parlamento, pelo menos de forma tão sistemática quanto o fez nos seus escritos extra parlamentares. Ainda assim deixou clara nas suas intervenções uma ideia para Portugal compreendendo um quadro político mais democrático e sobretudo um programa económico desenvolvimentista. A inclusão nesse programa de um sector público empresarial (ainda que limitado ao sector dos transportes), de uma reforma agrária, do proteccionismo pautal susceptível de fazer progredir a indústria (ainda que a sua defesa dos interesses industriais fosse menos marcada no parlamento que na actividade de publicista), de um impulso ao crescimento do sistema de crédito e, a presidir a tudo isso, uma estratégia de crescimento equilibrado centrado no mercado interno eram ideias que compunham um programa de desenvolvimento capitalista claramente distinto do posto em prática pelos governos regeneradores. Isto não obstante as sempre presentes dificuldades financeiras tenderem a polarizar o debate parlamentar com claro prejuízo da discussão das alternativas estratégicas que se apresentavam à sociedade portuguesa em meados de oitocentos.

É difícil avaliar com rigor o impacto e a eficácia da sua acção parlamentar, como o é em geral em relação aos economistas enquanto "subgrupo da cultura política" (Coats, 1981: 21). No entanto, é desde logo claro que ela não resultou no estabelecimento de uma nova hegemonia, eventualmente apoiada no poder social dos industriais, e não provocou inflexões importantes da política económica. A maioria das propostas importantes que apresentou ou não tiveram voto favorável da Câmara ou não chegaram sequer a ser votadas; isto é, passaram pela fase do diagnóstico dos problemas e pela de formulação de orientações para a acção mas por regra não atingiram a fase da implementação. Acresce que quando nas últimas décadas do século XIX se deu uma viragem na orientação da política económica num sentido favorável ao proteccionismo este pouco tinha a ver com os problemas discutidos e com as concepções de Marreca.

Apesar de o seu posicionamento político minoritário ${ }^{16}$ impor limites estreitos à eficácia da sua acção parlamentar o seu prestígio era considerável. Passos Manuel, seu distinto par na Câmara

16 Situação que compartilhava com outros professores de economia política que então tinham assento na Câmara dos Deputados, nomeadamente com José Alexandre de Campos e José Estevão. Todos eles, Marreca incluído, se situavam politicamente na extrema esquerda parlamentar, porventura porque consideravam que a mudança política para instituições historicamente mais avançadas era uma condição da mudança económica. A excepção era o deputado portuense Agostinho Albano da Silveira Pinto, que se revelou um defensor dos governos de Costa Cabral.

À parte Marreca, nenhum daqueles professores terá considerado seriamente as concepções económicas de List. 
dos Deputados, designou-o como "grande e primeiro economista deste país" (DCD, Sessão de 10.3.1852: 147) e Saraiva de Carvalho, discursando no parlamento duas décadas após a retirada de Marreca, referia-se ainda ao "distintíssimo escritor, que tem manuseado largamente as questões económicas e estatísticas, o sr. Oliveira Marreca [...] o abalizado economista" (DCD, Sessão de 11.5.1870: 399). Mais tarde, Rodrigues de Freitas, tal como Marreca professor de economia, político e deputado republicano referiu-se-lhe como "profundo pensador" (Freitas, 1889: 210). 


\section{Referências Bibliográficas}

Almodovar, António (1995) A institucionalização da economia política clássica em Portugal, Porto, Edições Afrontamento.

Augello, Massimo; Guidi, Marco (2002) La scienza economica in parlamento 1861-1922, Milano, Franco Angeli.

Augello, Massimo; Guidi, Marco (2005) Economists in Parliament in the Liberal Age (1848-1920), Aldershot, Ashgate.

Barreira, Cecília (1983) António Oliveira Marreca: notas em torno do seu percurso político e da ideação económico-social, in Oliveira Marreca, Obra económica, vol. 1, Lisboa, Instituto Português do Ensino à Distância, 7-28.

Bastien, Carlos (2002) Friedrich List and Oliveira Marreca: some odd coincidences, in Psalidopoulos, M; Mata, M. E. Economic thought and policy in less developed Europe, London/New York, Routledge, 232-246.

Blaug, Mark (1958) Ricardian economics: a historical study, New Haven, Yale University Press.

Castro, Armando (1980) O pensamento económico no Portugal moderno, Lisboa, Instituto de Cultura Portuguesa.

Chaves, Castelo Branco (1980) O romance histórico no romantismo português, Lisboa, Lisboa, Instituto de Cultura Portuguesa.

Coats, A. W. (1981) Economists in government, Duhram, Duke University Press.

Diário da Câmara dos Deputados, vários anos.

Esteves, Rui P. (2005) Finanças públicas, in Lains, Pedro; Silva, Alvaro F., História Económica de Portugal 1700-2000, vol. 2, Lisboa, Instituto de Ciências Sociais, 305-335.

Fetter, Frank W. (1980) The economist in Parliament, Duhram, Duke University Press.

Freitas, J. Rodrigues de (1889/1996) Um economista portuguez (António de Oliveira Marreca), in Freitas, J. Rodrigues de, Obras económicas escolhidas (1872-1889), tomo 2, Lisboa, Banco de Portugal, 205-249.

Gomes, Leonard (2003) The economics and ideology of free trade: a historical review, Cheltenham, Edward Elgar.

Krabbe, Jacob J. (1996) Historicism and organicism in economics: the evolution of thought, Dordrecht / Boston / London, Kluwer Academic Publishers

Lichnowsky, Felix (1845/2005) Portugal, recordações do ano 1842, Lisboa, Frenesi.

List, Friedrich (1841/1991) The national system of political economy, Fairfield, Augustus Kelley Publishers.

Martorell Linares, Miguel (2000) El santo temor al déficit, Madrid, Alianza Editorial.

Marreca, A. Oliveira (1838/1983), Noções elementares de economia política, in Oliveira Marreca, Obra económica, vol. 1, Lisboa, Instituto Português do Ensino à Distância, 67-197.

Marreca, A. Oliveira (1843/1983), Economia política - considerações sobre o curso d'economia política publicado em Paris em 1842 pelo Sr. Miguel Chevalier, in Oliveira Marreca, Obra económica, vol. 1, Lisboa, Instituto Português do Ensino à Distância, 231-286.

Marreca, A. Oliveira (1848/1983) Interesses industriais, in Oliveira Marreca, Obra económica, vol. 2, Lisboa, Instituto Português do Ensino à Distância, 37-158. 
Marreca, A. Oliveira (1850/1983) Sociedade Promotora da Indústria Nacional - Relatorio do Jurado, in Oliveira Marreca, Obra económica, vol. 2, Lisboa, Instituto Português do Ensino à Distância, 159-204.

Marreca, A. Oliveira (1853/1983), Parecer e memória sobre um projecto de estatística, in Oliveira Marreca, Obra económica, vol. 2, Lisboa, Instituto Português do Ensino à Distância, 205-313.

Mata, Maria Eugénia (2001) Finanças públicas e dívida pública, in Valério, Nuno, Estatísticas Históricas Portuguesas, vol. 2, Lisboa, INE., 657-712.

Mata, Maria Eugénia; Valério, Nuno (1995) História económica de Portugal - uma perspectiva global, Lisboa, Ed. Presença.

Say, Jean-Baptiste (1815) Catechisme d'economie politique, s/l, Maison Mame.

Say, Jean-Baptiste (1832) Cours complet d'economie politique pratique, Bruxelles, H. Dumont.

Serra, João B. (1980) Em defesa dos interesses industriais - António de Oliveira Marreca (1848-49), Análise Social, n. ${ }^{\text {os }}$ 61-62, 53-69.

Sideri, Sandro (1978) Comércio e poder, Lisboa, Edições Cosmos.

Wyplosz, Charles (1999) The culture of economic policy advice: an international comparison with special emphasis on Europe, in Mohr, Ernst, The transfer of economic knowledge, Cheltenham, Edward Elgar, 47-73. 